\title{
Future Trends in Project Management
}

\author{
Cátia Paredes \\ Department of Information Systems \\ University of Minho \\ Guimarães, Portugal \\ a71800@alunos.uminho.pt
}

\author{
Pedro Ribeiro \\ Department of Information Systems \\ University of Minho \\ Guimarães, Portugal \\ pmgar@dsi.uminho.pt
}

\begin{abstract}
Project management is a vast and complex area in which changes occur constantly. In this area there are several standards of good practices. The use of these standards and guidelines for project management increases the knowledge of managers and helps the organization to achieve better results. These are associated with several areas of knowledge or competencies, each with their own processes to develop. From the study of these standards a comparative / prospective model was developed. For the development of this model, 12 standards were studied. This work seeks to understand each of them, as well as the areas associated, and finally characterize the changes that have occurred between editions. This model intends to show the evolution in project management as well as its possible future. The objective would be the classification and structuring of the area and the concepts. Therefore, it is intended with this paper to contribute with a well-founded perception of the future development of project management, anticipating links between important themes for the development of this discipline.
\end{abstract}

Keywords—standards, guidelines, project management, future trends.

\section{INTRODUCTION}

Typically, companies develop several projects simultaneously, and the intention is to have the greatest success possible in each of them. This success can be accomplished by achieving all the requirements intended by stakeholders, whether internal or external entities. In this way, organizations are increasingly concerned with adopting good project management practices[1] [2]. Today, all companies rely on project management to succeed [3].

However, at the beginning, project management was only used to determine project timing, later becoming essential for survival [4]. According to the Project Management Institute (PMI), project management consists of meeting the requirements through the use of skills, techniques, tools and knowledge, executing them in the project processes [5].

As companies aim to achieve the best performance and quality, managers seek to improve and increase their knowledge, by using standards and guidelines [6][7]. Since there are several standards and guidelines, it would be advantageous to have a model that allows one to easily visualize the main rules and in which areas they are inserted, thus facilitating the work of organizations.

Following this introduction, will be explained a bit about project management. Subsequently, the third section presents the standards studied, as well as the changes that occurred from editing to editing. Finally, are presented the comparative / prospective model and the explanation of each evolution point presented in the model.

\section{Project Management}

As companies are born and grow, projects come naturally within each company. According to the PMI, "a project is a temporary effort undertaken to create a unique product, service or result." The temporary nature of the projects indicates that they have a defined beginning and end [5]. With this, a project is constituted by several phases in which each phase has a specific result. A project is divided in three major phases where the initial, intermediate and final task of project are grouped, with the corresponding project management outputs. The initial stage encompasses the genesis of the idea to the scope statement. The intermediate phase spans from devising a plan to its acceptance. The final stage include the approval and handover of the project product or service. These phases are depicted in Fig. 1.

Through the project concept, the definition of project management emerges. "Project management is the application of knowledge, skills, tools and techniques appropriate to project activities to meet their requirements."[5]. Therefore, project management is of overwhelming importance in a company [8]. If a company wants to make a change, the safest way is through project management. If project management is carried out effectively and efficiently, the business they are investing in will have more prominence, success and unique results [4]. As the importance of project management in a business increases, a manager's knowledge of good practices is also accumulated [4]. However, it has been difficult to establish this need to identify and preserve such good practices as companies do not always agree with the description of what would be "good practices" [4].

Project management can be used in several areas, for example the following:

- Implementation of IT and telecommunication;

- Engineering projects;

- Marketing projects;

- Process improvements.

Through the use of project management, companies will have greater satisfaction from the clients. Therefore, there will 


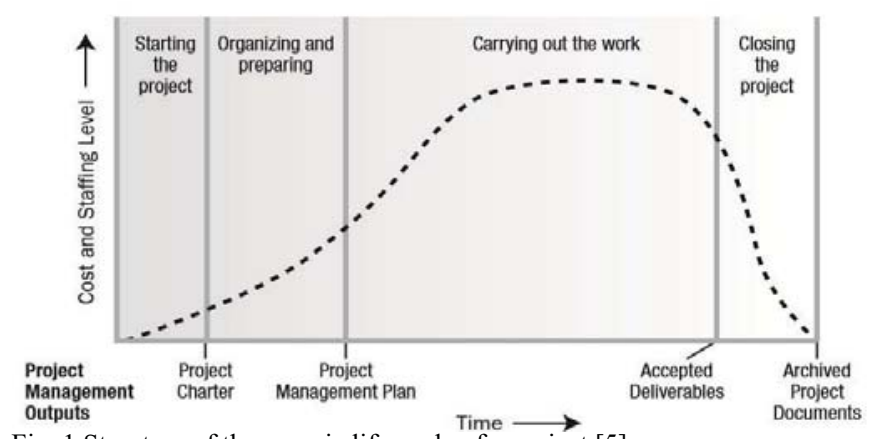

Fig. 1 Structure of the generic life cycle of a project [5].

be fewer improvisations and the decisions will have more quality. More notorious advantages will be the ability to lower the cost, which has impact in respecting the budgets estimated, as well as to allow deliveries to be made within deadlines. One of the greatest advantages of project management is that it can be applied to any type of project.

From the project and project management concepts comes the portfolio concept, viewed as a set of projects, subprojects and programs [9]. Thus, portfolio management facilitates the business goals management associated with the project and program organization management [10]. In this way, portfolio management has the following functions: project selection; resource allocation; monitoring and reporting; portfolios review and management of interdependencies [10].

As mentioned earlier, the portfolios are interconnected to the programs, thus, a program identifies a set of projects. The management of these projects is done in an integrated way, so as to obtain advantages that are not achieved if these projects were managed individually [9]. As before, through the definition of program, the concept of program management emerges, this works as a strategy change tool through a set of projects [10].

\section{Standards in Project Management}

In this section, the main objective is to present the standards studied and used for the development of this article. In subsection $\mathrm{A}$ is presented one figure that shows the standards studied. Next, section B describes the changes that occurred in each edition from the year 2000 .

\section{A. Allocation of standards by organization, people and processes}

In order to better understand project management practices and the concepts presented by studied standards, the proposed model show the frameworks organized by processes, people / competencies and organization (see Fig. 2).

As can be seen in Figure 2, the Organizational Competence Baseline (OCB) standard developed by IPMA is presented between the people / skills line and the organizational column. Also developed by the IPMA is the International Competence Baseline (ICB) standard and the Project Excellence Baseline (PEB) standard that is among the line of people / competencies and processes. In the organizational column, only the Organizational Project Management Maturity Model (OPM3)

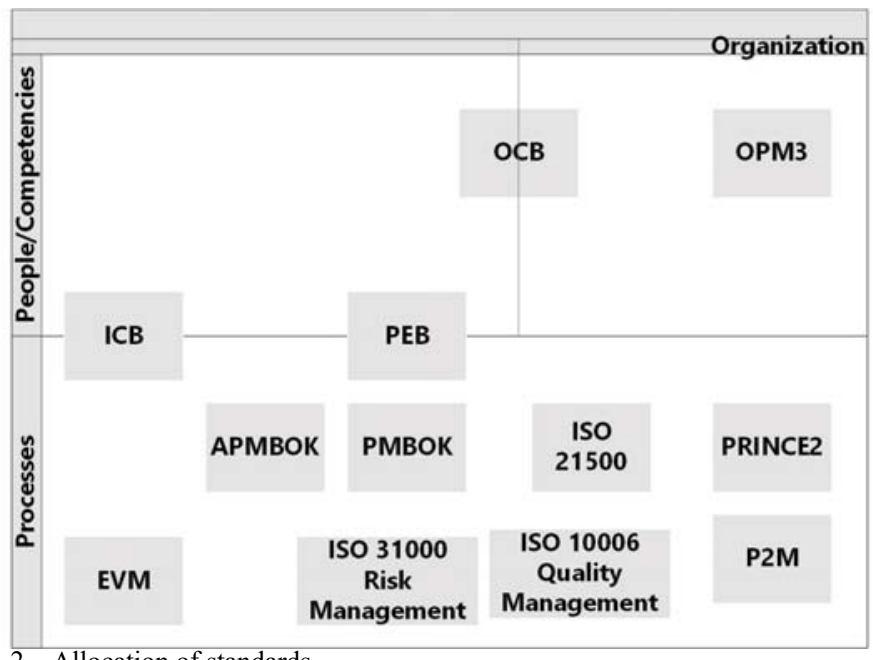

Fig. 2 - Allocation of standards.

is presented. As can be seen by the name, is a maturity model and this work is being developed by the PMI organization. Finally, in the line of processes, 3 ISO standards are presented, with ISO 31000 being a risk management standard, ISO 10006 a quality management standard and ISO 21500 a project management standard equivalent to the PMBOK guide. In the processes is also found the Project Management Body of Knowledge (PMBOK) standard that just like OPM3 was developed by PMI. The Association of Project Management Body of Knowledge (APMBOK) was developed by the Association of Project Management (APM). Next, Project and Program Management (P2M) is shown, this is a Japanese standard developed by the Japan Project Management Association (JPMA). Finally, PRINCE2 is presented and created by the Office of Government Commerce (OCG).

\section{B. Changes in standards editions}

This point is intended to refer some of the changes that have occurred between editions in the various standards. Editions will be taken into account as of the year 2000, to have a broad perspective on how frameworks have been changed.

\section{1) $\mathrm{PMBOK}$}

Once a standard is public, this one can suffer changes and revisions every 4 or 5 years. It will be taken into consideration the PMBOK 2000 (2nd edition) until the PMBOK 2017 (6th edition).

- $\quad$ PMBOK 2000 vs PMBOK 2004 - Briefly, the PMBOK 2000 is divided in 5 groups of processes: initiation process; planning process; control process; execution process and closure process and within these groups are defined 39 processes in total. These processes are associated to several areas of knowledge of Project Management, being in this edition, 9 areas of knowledge: project integration management; project scope management; project time management; project cost management; project quality management; project human resource management; project communications management; project risk management and project procurement management. In relation to PMBOK 2004, it maintains the same 5 groups of processes, but has 44 processes ( 2 eliminated and 7 added) and 13 of these 44 processes were renamed. The processes added were the 
following: develop the project launch term (section 4.1); develop the declaration of the preliminary scope of the project (section 4.2); monitor and control project work (section 4.5); closed the project (section 4.7); create the analytical structure of the project (section 5.3); estimate of activity resources (section 6.3); managing the project team (section 9.4). In relation to the number of areas of knowledge this is maintained.

- PMBOK 2004 vs PMBOK 2008 - In terms of process groups, they continue to be the 5 referred to in the PMBOK 2000. In terms of processes they went from 44 in the PMBOK 2004 to 42 in the PMBOK 2008. Two processes were eliminated, two were added and six were reconfigured in four processes in the knowledge area in procurement management of the project. The processes eliminated were: develop a preliminary scope statement (section 4.2) and scope planning (section 5.1). In terms of new processes are: obtain requirements (section 5.1) and identify stakeholders (section 10.1). However, most of the process has been renamed.

- PMBOK 2008 vs PMBOK 2013 - The groups of processes remain the same 5. In terms of knowledge area they went from 9 to 10 , increasing the area of "Stakeholders Management". The processes added were: planning scope management (section 5.1); planning term management (section 6.1); planning cost management (section 7.1); planning quality management (section 8.1); planning human resources management (section 9.1); controlling communications (section 10.3). The processes of "Identifying stakeholders", "Managing stakeholder expectations" are moved to the new area of stakeholder management. In addition to these two processes, this area contains: planning stakeholders management and controlling stakeholders management. From the 5 th edition is found in section 6.7.2.1 of the PMBOK an approach to EVM technique as a cost control.

- PMBOK 2013 vs PMBOK 2017 - Throughout the other editions PMI has been concerned with aligning the PMBOK with other existing standards. An important point that changed in the PMBOK was chapter 3. This chapter starts to refer what competences and role project managers should have, thus including the talent triangle. The areas are the same as the PMBOK 2013, as well as the process groups. The number of processes has increased to 49, with the new processes being: managing project knowledge (section 4); implementing risk responses (section 11) and controlling resources (section 9). One of the most important changes in the 6 th edition is the inclusion of agile practices. Agile will be referred to explaining how these practices are applied to the project.

\section{2) $A P M B O K$}

The editions to be considered in this point refer to the year 2000, followed by the fifth edition published in 2006 and, finally, the sixth edition published in 2012.

- APMBOK 2000 vs APMBOK 2006 - Essentially from one version to another, several points were renamed. On the other hand, new points have been inserted. Portfolio
Management was one of the topics that emerged in the fifth edition, thus no longer being part of Program management point. Of note, in the topic "Process success criteria", this was renamed to "Process success and benefits management", with additions of new benefits. Next, a new topic was added, "Development", where in the previous version the requirements management topic was deleted. In the topic "Organization and Governance and People and the Profession", two new topics have been added in each.

- APMBOK 2006 vs APMBOK 2012 - The main difference passes through the constituent sections of the guide. In APMBOK 2006, the sections are: project management in context; planning the strategy; executing the strategy; techniques; business and commercial; organization and governance; people and the profession. While, APMBOK 2012 only has 4 sections: context; people; delivery and interfaces.

3) $P 2 M$

The versions to be taken into consideration will go through the 1st edition in 2001, 2nd edition in 2004 and finally 3rd edition in 2017.

- P2M 2001 vs P2M 2004 - The first visible change, is that the first edition consists of 87 pages, and the second edition consists of 214 pages. In the first edition there is the definition of the programs and the description of several concepts of the same. Followed by the presentation of several definitions of concepts associated with integration management. Finally, the 11 management areas are described. While in the second version, the 11 domains are presented in detail, relatively to strategy, finance, risk and value for communications.

- P2M 2004 vs P2M 2017 - In the third edition, they return to define several points associated with the projects and programs management. The domains are changed and become areas in project management, these areas are related to ISO 21500: 2012 standard. Next, several concepts are defined and described about business management, knowledge management and human resources management.

\section{4) ISO 21500}

No change will be examined, because ISO 21500 is a standard that was edited in 2012 and has no other version.

\section{5) PRINCE2}

PRINCE2 was introduced in 1996, with a new version in 2002, followed by an update in 2005 and a new version in 2009. In 2017 PRINCE2 underwent some changes again. It will be made a summary of the changes that took place only after 2005.

- PRINCE2 2005 vs PRINCE2 2009 - The main change from one version to another is the emphasis on the introduction of the constituent principles of PRINCE2. In the 2005 version, the principles were referred to in an implied way, and in the 2009 version they were referred to in a clear way. The principles referred to above are: continuous business justification; learn from experience; defined roles and responsibilities; manage by exception; 
manage by stages; focus on product; and tailor to suit environment. In 2005, "Planning" was defined as a process, but in version 2009 is defined in the "Themes", that is, the number of processes went from 8 to 7 . The second sharp change was the reduction of the number of pages, the version of 2005 has around 450 pages passing to about 340 in version 2009. This fact arose from an elimination of repeated points and the addition of a more simplified language. A third, clear change was the renaming of "Components" to "Themes".

- PRINCE2 2009 vs PRINCE2 2017 - Although a new version has emerged, it's important to emphasize that the basis of PRINCE2 remains the same, with the number of processes, themes and principles remaining the same. PRINCE2 eventually changed due to changes in other books. In 2015, the book "PRINCE2 Agile" was published, so PRINCE2 needed to be modified in order to better explain the approach to agile projects. The other changes that have taken place include improvements to certain points such as the elimination of the Annex Risk categories, elimination of the Techniques point, and others.

6) $O P M 3$

The versions considered in this point refer to 2003, being the second edition published in 2008 and, finally, the third edition published in 2013 .

- OPM3 2003 vs OPM3 2008 - One of the main changes was the alignment with the 4th edition of the PMBOK, published in 2008, and with the 2nd edition of the Portfolio and Program Management Standards. Through this alignment, various capacities and good practices have been edited or renewed. In terms of good practice categories, they went from 6 to 9, adding the following knowledge areas; organizational enables and business outcomes. Regarding the Self-Assessment Method, this has been improved and there were added questions. Regarding the changes in the structure, they can be verified in Fig. 3.

\begin{tabular}{|c|c|}
\hline 2003 Edition Sections & Second Edition Sections \\
\hline $\begin{array}{l}\text { Section } 1 \text { - Introduction to OPM3 } \\
\text { Chapter } 1 \text { Foundational Concepts } \\
\text { Chapter } 2 \text { User Overview }\end{array}$ & $\begin{array}{l}\text { Section } 1 \text { - Introduction to OPM3 } \\
\text { Chapter } 1 \text { Introduction } \\
\text { Chapter } 2 \text { Foundational Concepts }\end{array}$ \\
\hline $\begin{array}{l}\text { Section } 2 \text { - Understanding the Model } \\
\text { Chapter } 3 \text { Best Practices } \\
\text { Chapter } 4 \text { The Organizational Project Management } \\
\text { Processes }\end{array}$ & $\begin{array}{l}\text { Section } 2 \text { - Understanding the Model } \\
\text { Chapter } 3 \text { The OPM3 Cycle } \\
\text { Chapter } 4 \text { The Organizational Project Management } \\
\text { Processes }\end{array}$ \\
\hline $\begin{array}{l}\text { Section } 3 \text { - Using the Model } \\
\text { Chapter } 5 \text { The OPM3 Directories } \\
\text { Chapter } 6 \text { The OPM3 Cycle }\end{array}$ & $\begin{array}{l}\text { Section } 3 \text { - Using the Model } \\
\text { Chapter } 5 \text { The OPM3 Construct } \\
\text { Chapter } 6 \text { The OPM3 Best Practices }\end{array}$ \\
\hline $\begin{array}{l}\text { Section } 4 \text {-Appendices } \\
\text { Appendix A The Program Management Institute } \\
\text { Standards-Setting Process } \\
\text { Appendix B Evolution of the organizational project } \\
\text { management maturity model. } \\
\text { Appendix C Contributors and Reviewers of the OPM3 } \\
\text { Appendix D OPM3 Self-Assessment } \\
\text { Appendix E Comprehensive Assessment: Detail } \\
\text { Substeps } \\
\text { Appendix F Best Practices Directory } \\
\text { Appendix G Capabilities Directory } \\
\text { Appendix H Improvement Planning Directory } \\
\text { Appendix I Program and Porttolio Management Process } \\
\text { Model }\end{array}$ & $\begin{array}{l}\text { Section 4-Appendices } \\
\text { Appendix A Second Edition Changes } \\
\text { Appendix B Evolution of the OPM3 Maturity Model } \\
\text { Appendix C Contributors and Reviewers of OPM3 } \\
\text { Second Edition } \\
\text { Appendix D Self Assessment Method } \\
\text { Appendix E Online Tools } \\
\text { Appendix F OPM3 Case Study } \\
\text { Appendix G Assessment and Improvement How-To } \\
\text { Guide }\end{array}$ \\
\hline
\end{tabular}

Fig. 3 Changes in OPM3 from the first to the second edition [11]
- OPM3 2008 vs OPM3 2013 - With the publication of the 5th edition of the PMBOK and the 3rd edition of the Program and Portfolio Management Standards, the 2013 edition of OPM3 was aligned with them and good practices and skills were reviewed. As for the SelfAssessment Method, it has been aligned with the 3rd edition of the Program and Portfolio Management Standards. Regarding the changes in the structure, they can be verified in Fig. 4 .

7) $I C B$

The versions to be considered in this point are from 2001 onwards. Thus, the ICB has an edited version in 2001, this being its 2nd edition. Then, a 3rd version was released in 2006 . Finally, a 4th version was released, being this the last edition, in 2015.

- ICB 2001 vs ICB 2006 - The biggest difference between these two versions is that in version 2.0 the skills are presented in the form of a sunflower, while in version 3.0 the competences are presented in the form of "eye of competences". The competencies presented in version 2.0 are: general impression; personal attitude and knowledge and experience. The Knowledge and experience competency contains 42 elements, the General impression competence contains 10 aspects and the Personal attitude competence contains 8 aspects. On the other hand, the competencies presented in the "competency eye" are: contextual competences; technical competences and behavioral competences.

\begin{tabular}{|c|c|}
\hline Second Edition & Third Ealtion \\
\hline $\begin{array}{l}\text { Pretace } \\
\text { Execultive summary view of OPU3 }\end{array}$ & $\begin{array}{l}\text { Pretace } \\
\text { This section communicates to Erecutives and Practlioners what is } \\
\text { contaned in this book }\end{array}$ \\
\hline $\begin{array}{l}\text { Section } 1 \text { introduction to OPM3 } \\
\text { Chapter } 1 \text { Introduction } \\
\text { Chapter } 2 \text { Foundational Concepts }\end{array}$ & $\begin{array}{l}\text { Section } 1 \text { Introduction } \\
\text { Section } 2 \text { Foundational Concepts }\end{array}$ \\
\hline $\begin{array}{l}\text { Section } 2 \text { Understanding the Model } \\
\text { Chapter } 3 \text { The OPM3 Cydle } \\
\text { Chagter } 4 \text { The Orgarizasonal Project Management frocesses }\end{array}$ & 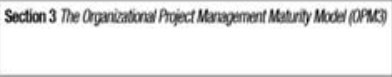 \\
\hline $\begin{array}{l}\text { Section } 3 \text { Using the Model } \\
\text { Chapter } 5 \text { The OPMOB Construct } \\
\text { Chapter } 6 \text { The OPM3B Best Proctices }\end{array}$ & $\begin{array}{l}\text { Section } 4 \text { Acquire Knowledge } \\
\text { Section } 5 \text { Perform Assessment } \\
\text { Section } 6 \text { Marage Improvement }\end{array}$ \\
\hline 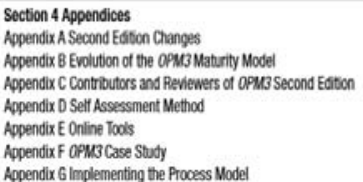 & 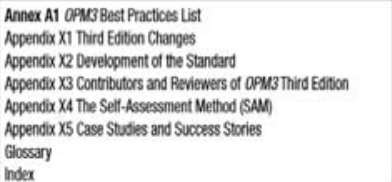 \\
\hline
\end{tabular}

Fig. 4 Changes in OPM3 from the second to the third edition [12]

- ICB 2006 vs ICB 2015 - Previously, three competencies have been presented that constitute the "competence eye" of version 3.0 of the ICB. However, in version 4.0 of the ICB these same competencies have been changed. The "eye of competence" is maintained, however, competencies have become perspective competence elements, people competence elements and practice competence elements. Therefore, the Perspective competence contains 5 elements, the People competence contains 10 elements and the Practice competence contains 14 elements.

\section{8) $P E B$}

No change will be presented, as PEB is a recent standard that was only created by the IPMA in 2016 . 


\section{9) $O C B$}

No change will be presented, as the OCB is a recent standard that was only created by the IPMA in 2016.

10) $E V M$

- EVM 2000 vs EVM 2010 - The editions taken into account were published in 2000 and 2010, being these the second and fourth edition, respectively.

- From the second edition to the fourth edition, one chapter has been deleted and four added. The chapters added, in the fourth edition, were chapter 1 "If earned value is so hot ...", chapter 10 "Employ earned value measurement on project procurements", chapter 13 "Using earned value metrics to manage a portfolio of projects " and chapter 14" Implement simple earned value on all projects ". While the eliminated chapter, in the second edition, was chapter 11 "Reengineering the earned value process for the private sector". That is, EVM started to differentiate its use in portfolios and projects and how to become used in all types of projects. As such, it no longer focuses in the private sector.

\section{1) ISO 10006}

The editions taken into account were published in English in 2003 and 2017, being the second and third edition, respectively.

- ISO 10006:2003 vs ISO 10006:2017 - From one edition to the next there were only two enlarged chapters and two with altered designations. The new chapters were chapter 4.3 "Project quality management processes" and chapter 4.4 "Quality plan for the project". While the name changes occurred in subchapter 7.8 of "Purchasing-related processes" to "Procurements processes" and in subchapter 8.3.1 of "Improvement by originating organization" to "Improvement by the project organization".

\section{2) ISO 31000}

No change will be made, because ISO 31000 is a standard that was edited in 2009 and has no other version.

\section{Comparative / Prospective MOdeL}

In Fig. 5 is illustrated a comparative/prospective model. This model is divided horizontally between organization, people / skills and processes, whereas vertically is divided into evolution and future. In order to facilitate the understanding of existing evolution in project management, a timeline has been added that varies between 2009 and 2025. This evolution, can be observed until the year 2018. Then the possible changes will be explained and justified. The evolution presented in the model, shows the progress from 2009 onwards, and in which years the standards were edited. Those standards that feature more than one edition, show some of the changes that occurred between editions. Relative to the future, the stated points are referring to technologies/methods which may be associated to project management or may even become more relevant if already in use. This model intents to present what can be added to project management and what happened so far. Although there is a division in year 2017, it does not mean that the standards used so far will no longer exist, but rather that new technologies/methods may be associated to them or to project management. The blue lines, presented in the model, refer to the changes occurred between editions of the standards. On the other hand, the orange lines and the orange letters refer to complementary standards between them. Finally, the purple line refers to differences between standards, and the squares of PMBOK and ISO 21500 in green mean they are equivalent to each other.

As stated earlier, on the right side is presented the future in project management. In this way, all the points referred to as future in Fig. 5 are explained below.

1) Outcome Driven Projects: This point of evolution in the area of project management is suggested through the BIG10 team of the PMI Netherlands Chapter and Hans Gemuenden and Yvonne Schoper [13][14]. This type of projects are more complex and externally exposed, unable to achieve success with focus only on scope, time and cost. Success in these projects, it will be measured by the contribution to the business itself. The search for long-term results is increasing the responsibility of engineering organizations, IT organizations, and other organizations responsible for projects [14]. As such, there are crucial points for their success, like, stakeholder management, teamwork and a strategic approach associated with the project's rapid delivery capability [13]. Therefore, there will be an increased importance with respect

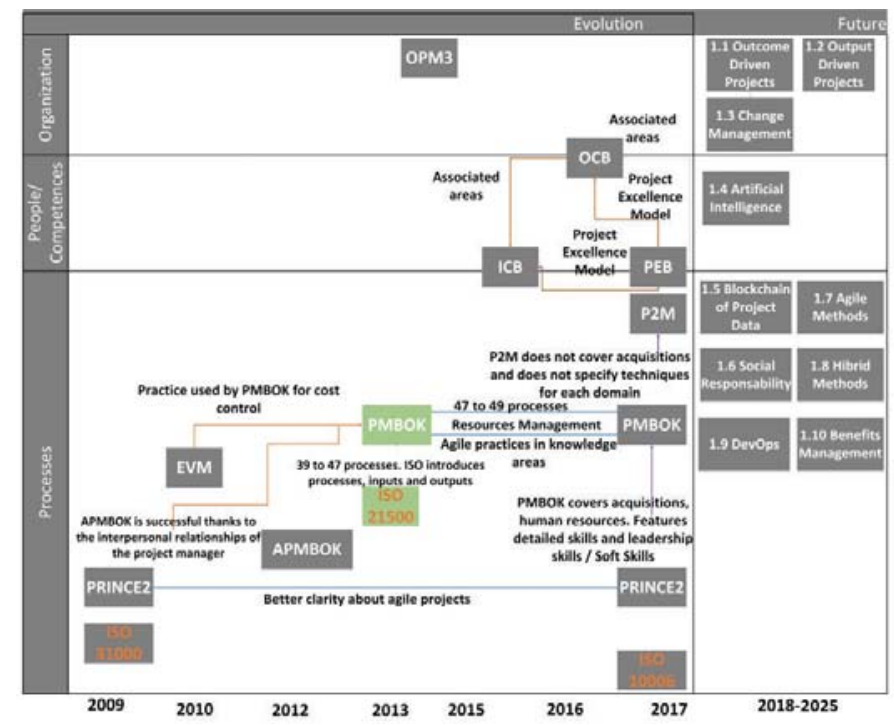

Fig. 5 Comparative/Prospective model

to the sustainability and management of the projects, as well as, the increase in the emphasis of the value and benefit of the project. Due to this situation, it will be necessary to develop evaluation and monitoring tools for value, benefit, sustainability and project management [14].

2) Output Driven Projects: This point in the evolution of project management was also referenced through the BIG 10 team of the PMI Netherlands chapter. Compared to the previous point, this is a simpler project and almost considered as a project of production processes. Consequently, these have a clearer and defined scope, and their result can be controlled through the "iron triangle", despite being already an old method. For this reasons, it is necessary to have good technical knowledge, as well as the existence of hard / soft skills. [13] 
3) Change Management: Nowadays, projects are increasingly complex and therefore are susceptible to more and more changes throughout their development. For that, management of these changes is necessary [15][16]; it contributes for frequent communication between stakeholders and people involved in the project, keeping them calm during the process. It also serves to make the changing planning and to manage the plan while it's being developed. Thus, it is higly necessary to have resilient managers in project management due to the constant changes that projects are subject to.

4) Artificial Intelligence: artificial intelligence is understood as the name given to technology for the development of machines and software, in which they can help humans make decisions [17]. This software has a capacity similar to human capacity, meaning that it is capable of making its own decisions without needing human beings. According to Pressman and Maxin, authors of the book "Software Engineering: A Practitioner's approach", this will be a bridge between project management and software [18]. The insertion of the Artificial Intelligence in the management will lead to positive changes, like a reduction of errors, since the software will have greater sensitivity to verify any type of change in the production systems, information and technology. This reduction of erros is directly related with an increase of production. Finally, support in the decision wil be improved, since, one of the objectives of artificial intelligence is to define the performance of the software so that can help the manager to make decisions.

5) Blockchain of Project Data: This point of evolution is supported by the Association for Project Management (APM), ARUP and UCL, through the writing of an article. ARUP is an independent firm of project managers, designers, gliders, engineers, consultants and technical specialists [19]. Thus, Blockchain is a new technology that became a non-existent web integration useful for payments, invoking and transferring assets and transferring discrete units [20] [21]. In other words, it is a technology that allows the transfer of data that is safe, auditable and resistant to inter-clusters. From the moment that blockchain is implemented in projects, it became possible to have a secure communication between the manager and all participants, being this a national or international project. With this untouchable system, less prone to human errors, hacking attacks and data loss, is thus possible to define requirements, budgets, delivery times quickly and protected.

6) Social Responsibility: This is a point referenced by the association APM, ARUP and UCL [19]. According to these three entities, the PMBOK will have a new chapter called social responsibility [19]. According to Nuno Fernandes, author of the master's thesis on corporate social responsibility, social responsibility has several definitions and sometimes it is confused with other concepts such as ethics, philanthropy, etc. It also states that a company must be socially responsible in its daily life, meaning, the company must respect human rights, defend the environment and contribute to social cohesion [22]. There are several reasons for companies to adopt these social responsibility policies, like, for example, the reason for imposition, that is, when the company has to adopt these policies because the law obliges them. Being the PMBOK a good practice guide, it aims to help companies realize what needs to be done. Therefore, it is important to mention the topic of social responsibility in one of its chapters. This is because people and other organizations want to do business with companies that provide transparency and ethical values. With this, projects should also be monitored with the perspective of ensuring that they meet the legislative, legal and environmental requirements.

7) Agile Methods: This point of evolution is supported by IPMA and PMI. Agile methods have become widely used by project managers. Agile methods have emerged as the opposite of traditional ones. Thus, the traditional methods are plans made at the beginning of the project, in which they argue that all problems can be predicted and the processes reused making the development of the activity efficient and predictable [23] [24]. Consequently, this method should only be used in projects that have stable requirements. On the contrary, agile methods are used in projects where requirements can be changed, teams are made up of a few elements, delivery times are short, code can change over time with low cost and the rapid development of the project is fundamental [25]. With this, the PMBOK and PRINCE2 started to refer to the agile methodologies in their manuals, creating addicional books as a complement to the main ones. There are numerous agile methodologies that can be used in projects such as SCRUM, Kanban, XP, among others. As such, projects today are reaching increasingly higher levels of complexity, increasing due to the growth and diversification of stakeholders, the breadth in project scope, the diversification of cultures and virtualization of the projects, the increase of the amount of information and the higher impact on businesses [13]. Therefore, these methodologies are used in the area of Information and Communication Technology, in order to deal with the complexity that the projects are currently reaching.

8) Hybrid Methods: This point is supported by both IPMA and BIG10 [14][13]. As mentioned previously, in the world of project management there are traditional methods and agile methods. Agile methods, can be applicable in different points of the project or even different types of project [26]. Thus, from the combination of these two, came the hybrid methods. For these to be used, it is necessary to have some factors in consideration such as requirements, division of roles, errors / failures, quality and documentation. First, it is crucial to clarify the cultural factor of the organization that intends to adopt it and then to make a planning of what to use of both methods (agile and traditional). This is a method that has been around for some time, and will be increasingly developed over time and higly used in project management.

9) DevOps: DevOps is a term with several definitions given by several authors. However, most define DevOps as a term that specifies the collaboration between software development and operations. According to Lucy Lwakatare, Penners and Dyck defines DevOps as "a mindset, encouraging cross-functional collaboration between teams - especially development and IT operations - within a software development organization, in order to operate resilient systems and accelerate the delivery of changes "[27] [28]. Therefore, DevOps integrates the two teams, in which the development team intends to deliver the software in the shortest time possible and always looks for more agile methods to develop it while the operations team tries to make sure that the software is effective and stable. According to the previous authors, this integration and improvement of team communication will lead 
to faster delivery times and higher quality associated with production.

10) Benefits Management: The benefits are directly linked to changes in a project and delivery of outputs. Usually when a change occurs it will be because it will bring an associated benefit, although there may be some negative impacts that are not avoidable in these changes. On the other hand, a project that has been delivered effectively will not necessarily be synonymous of benefits. Thus, benefits management will become very important in this area, and so the benefits will be structured in the beginning of the project and associated with a business case. According to the APM, benefits management will go through 5 steps: define benefit management plan; identify and structure benefits; plan benefit realization; implement change and realize benefits [29]. With the introduction of benefits management, the question arises as to how the benefits of the proposed project would be evaluated. To this end, according to the PMI, a measurement tool called "quality of target benefits" would be developed. With the emergence of this tool, there would be associated criteria so that they have to achieve certain goals. These goals need to be SMART - Specific, Measurable, Attainable, Relevant and Time oriented [30].

\section{CONCLUSION}

Due to the needs of the organizations, it is necessary to apply principles of project management through the use of standards. These standards will help to achieve the excellence and maturity of project management, thus making it possible to increase the organization's success changes.

In this way, a study of 12 standards was carried out and verified how each one evolved over the years. A survey of the opinions of authors and associations about the future of project management was then made. From Fig. 5, we can conclude that project management will evolve in terms of organization, people / skills and processes. In relation to the organization, evolution wil be divided into two types of projects (Output Driven and Outcome Driven). Another independent point of evolution is Change Management, due to the increased complexity in the projects, thus leading to constant changes during the development of the projects. In terms of people / competencies, evolution will depend on artificial intelligence due to the development of software capable of helping the human make decisions. Finally, key points in the evolution of project management go through the hybrid methods, as they are the combination of traditional and agile methods, and the management of benefits due to the constant changes that occur in the projects. In addition to these, blockchain and agile methods are presented, which, despite being already known and used, will become more relevant to project management. Finally, the DevOps that will be associated with agile methods and social responsibility will become a chapter of the PMBOK.

With this, the model allows to reach the objective defined in the work. This involves classifying and structuring the area and associated concepts, as well as predicting how project management is evolving and what concepts will be most relevant.

\section{ACKNOWLEDGEMENTS}

This work has been supported by COMPETE: POCI-010145-FEDER007043 and FCT - Fundação para a Ciência e Tecnologia within the Project Scope: UID/CEC/ 00319/2013.

\section{REFERENCES}

[1] A. M. Dahie, A. A. Osman, and A. A. Omar, "The Role of Project Management in Achieving Project Success : Empirical Study The Role of Project Management in Achieving Project Success : Empirical Study from Local NGOs in Mogadishu-Somalia," no. September, 2017.

[2] A. Sousa-poza, "P ROJECT M ANAGEMENT See What," vol. 36, no. 2, 2005.

[3] J. Pollack and C. Algeo, "The Contribution of Project Management and Change Management to Project Success," no. December, 2015.

[4] H. Kerzner, Gestão de Projetos - 3ed: As Melhores Práticas. 2017.

[5] PMI, A Guide to the Project Management Body of Knowledge, vol. 5. 2013.

[6] G. J. Skulmoski, A. Dhabi, U. A. Emirates, and F. T. Hartman, "Information Systems Project Manager Soft Competencies: A ProjectPhase Investigation," vol. 41, no. 1, pp. 61-80, 2010.

[7] D. O. V Dvir, A. Sadeh, and A. Malach-pines, "PROJECTS AND PROJECT MANAGERS: THE RELATIONSHIP BETWEEN PROJECT MANAGERS' PERSONALITY, PROJECT TYPES, AND PROJECT SUCCESS,” pp. 36-48, 2006.

[8] O. I. Tukel et al., "February 2011 A Fresh Look at the Contribution of Project Management to Organizational Performance Monique Aubry and Brian Hobbs Single-Loop Project Controls: Reigning Paradigms or Tarek K . Abdel-Hamid PMP $®$ Certification as a Core Competency : Necessar," vol. 42, no. 1, 2011.

[9] V. R. Vargas, "Gerenciamento de Projetos: Estabelecendo Diferenciais Competitivos," 2016.

[10] R. Kay, "The PMQ Primer A Guide to Passing the APM Project Management Qualification," 2017. [Online]. Available: https://books.google.pt/. [Accessed: 09-Jan-2018].

[11] PMI, Organizational Project Management Maturity Model (OPM3®). 2008.

[12] PMI, Organizational Project Management Maturity Model (OPM3®) Third Edition. 2013.

[13] BIG10, “The Project Manager 2020.” 2016.

[14] H. Georg Gemuenden and Y. Schoper, "Future Trends in Project Management," 2015.

[15] R. By, "Organisational Change Management: A Critical Review," no. December 2005, 2014.

[16] R. C. Jalagat, "The Impact of Change and Change Management in Achieving Corporate Goals and Objectives: Organizational Perspective," no. November, 2016.

[17] M. M. Mijwel, "History of Artificial Intelligence Yapay Zekânın T arihi," no. April 2015. pp. 3-4, 2015.

[18] R. S. Pressman, Software Engineering: A Practitioner's Approach, Seventh. .

[19] Arup, APM, and UCL, "Future of Project Management," 2017.

[20] Ž. Turk and R. Klinc, "Potentials of Blockchain Technology for Construction Management," Procedia Eng., vol. 196, no. June, pp. 638645, 2017.

[21] M. Swan, Blockchain: Blueprint for a New economy. 2015.

[22] N. M. Fernandes, “A responsabilidade social das empresas - a dimensão interna: uma ferramenta para a criação de valor,” 2010.

[23] S. Parente, "2018 Project Management Symposium Papers," pp. 2-5, 2018.

[24] D. Šmite, N. BredeMoe, and P. J. Ågerfalk, Agility Across Time and Space. 2010.

[25] M. D. S. Soares, “Comparação entre Metodologias Ágeis e Tradicionais para o Desenvolvimento de Software," INFOCOMP J. Comput. Sci., vol. 27, no. 2, p. 1, 2003. 
[26] W. Chaves and D. S. Carvalho, "Análise do paradigma híbrido na indústria de software," vol. 11, no. 2, 2014.

[27] L. E. Lwakatare, DevOps adoption and implementation in software development practice : concept, practices, benefits and challenges. 2017.

[28] E. Larson, A. Brockmeier, R. Larson, and S. Heidorn, "2018 Trends in Business Analysis and Porject Management."
[29] APM, "Benefits Management." [Online]. Available: https://www.apm.org.uk/body-of-knowledge/delivery/scopemanagement/benefits-management/. [Accessed: 20-Aug-2018].

[30] PMI, "Project benefit management," 2014. [Online]. Available: https://www.pmi.org/learning/library/project-benefit-management-8957. [Accessed: 20-Aug-2018] 